\title{
Young carers in Sweden-A pilot study of care activities, view of caring, and psychological well-being
}

\author{
Ulrika Järkestig-Berggren $^{1}$ (D) | Ann-Sofie Bergman ${ }^{1}$ (D) । Maria Eriksson ${ }^{2}$ (D) | Gisela Priebe ${ }^{3}$
}

${ }^{1}$ Department of Social Work, Linnaeus University, Sweden

${ }^{2}$ Department of Social Sciences, Ersta Sköndal Bräcke University College, Stockholm, Sweden

${ }^{3}$ Department of Psychology, Lund University, Lund, Sweden

Correspondence

Ulrika Järkestig-Berggren, Associate Professor, Department of Social Work, Linnaeus University, Kalmar, Sweden.

Email: ulrika.jarkestig-berggren@lnu.se

Funding information

Children's Welfare Foundation Sweden

\begin{abstract}
Children who have parents with any kind of illness may become young carers who take a responsibility not expected of children for household tasks, or personal or emotional care for parents and siblings. So far, little is known about children in Sweden who are at risk of becoming young carers. The aim of this article is therefore to explore the extent and impact of children's caring activities as reported in a pilot study by a sample of children in Sweden. A number of international questionnaires measuring the amount of caring activities, impact of caring, quality of life, and psychological well-being were translated and combined into a survey. The pilot survey was completed by 30 children 10-18 years of age. Also, when completing the survey, the children were interviewed concerning their experiences of caregiving. The participants report on a group level emotional symptoms such as fear and nervousness above the clinical cut-off value. They also rate a lower level of caring compared with findings from the United Kingdom, but they report a higher degree of negative impact of caring than young carers in the United Kingdom.
\end{abstract}

\section{KEYWORDS}

care activities, child protection, impact of caring, psychological wellbeing, young carers, youth

\section{1 | INTRODUCTION}

Children may take on responsibilities for household care and personal and emotional care for parents and siblings when there are unmet needs in the family due to various problems of the parents, such as mental health issues, drug addiction, and physical illness (Pakenham, Chiu, Bursnall, \& Cannon, 2007). So far, little is known about the children in Sweden who are young carers, the caring tasks they do, how they perceive their caring, and the psychological well-being of the children. Young carers can be defined as:

young people under the age of 18 who provide care, assistance or support to another family member. They carry out, often on a regular basis, significant or substantial caring tasks and assume a level of responsibility that would usually be associated with an adult. The person receiving care is often a parent but can be a sibling, grandparent or any other relative who is disabled, has some chronic illness, mental health problem or other condition connected with a need for care, support or supervision. (Leu \& Becker, 2017, p. 750)

When defining young carers, there are differences among countries concerning the age interval included: in the United States, up to the age of 18 years; the United Kingdom, up to the age of 17 years; and Australia, up to the age of 24 years of age (Cass, Smyth, Hill, Blaxland, \& Hamilton, 2009; Cunningham, Shochet, Smith, \& Wurfl, 2017). In Sweden, no formal definition of young carers exists, therefore we have adopted the definition above mentioned for our study. We refer to young carers as children up to the age of 18 , adjusting to Swedish law that grant children and adults different kinds of support when being a caregiver. Adults from 18 years are granted support according to the Social Services Act as a caregiver, whereas children are not. An early 
study (Becker et al., 1995) suggested that there has been an understanding among professionals and researchers in Sweden that the welfare state protects children from any kind of child labour, and also that general welfare services provide children and their parents with ample resources for a positive childhood upbringing such as child benefits for all families, nursery schools for children, and rights to parental leave. The idea of a comprehensive and protective welfare system may conceal the impact of deinstitutionalization and fragmentation of support systems, for example, that the family has been reintroduced as the main responsible entity to give support for adult persons with various kinds of needs (Bergman, 2016; Trondsen, 2013). The nuclear family as the major support provider, whether it is for children or adults, has not always been recognized by society, or by research in Sweden. In some other countries, however, prominently England and Australia (Leu \& Becker, 2017; Pakenham \& Cox, 2015), practice and research has found means to identify children who become young carers, and support for those children has been developed. Depending on measurement used, estimates from Australia, United Kingdom, and the United States indicate that 2$8 \%$ of the population of children under 18 years of age are young carers (Cass et al., 2009; Leu \& Becker, 2017). A Swedish regional survey in the general population in the southwest of the country, aimed at children ages $15-16$, found that $7 \%$ of the children in the study reported a high amount of caring activities (Nordenfors, Melander, \& Daneback, 2014).

In Sweden, there are provisions for parents within the Social Services Act (law 2001:543) to provide help with domestic tasks and to promote the welfare for children and protect children from any kind of neglect. However, due to the lack of recognition in research, it still remains to be explored as to what extent children who take on caring activities are aided.

\section{2 | AIM}

The overarching aim of this study is to explore the extent and impact of children's caring activities as reported by a sample of children in Sweden. More specifically, the study sought answers to the following questions:

a. What kind and amount of caring activities do children report?

b. What level of psychological well-being do children report?

c. Are there any differences in children's reports due to age and gender?

d. How do children who report a high degree of caring activities perceive and describe the impact of their caregiving?

\section{1 | Young carers in research}

Children may become young carers due to unmet needs in the family and parent's problems (Cunningham et al., 2017; Pakenham \& Cox, 2015). Low income occurs as a factor that both influence the process of becoming a young carer and the level of caregiving undertaken (Kallander et al., 2017; Smyth, Cass, \& Hill, 2011). Children's caring activities also seem to be related to the offered support of the welfare system, when parents do not get sufficient support from society (Cunningham et al., 2017; Kallander et al., 2017; Leu \& Becker, 2017; Pakenham \& Cox, 2015).

Children's amount of caring can be described as a continuum starting with a low level of caring at 1-19 hr per week up till a high level of caring at $50 \mathrm{hr}$ per week or more (Becker, 2007). Joseph, Becker, Becker, and Regel (2009b), who constructed a questionnaire for identification of young carers in the United Kingdom, found that the caring tasks can be divided into six domains: personal care, sibling care, domestic chore, emotional care, household management, and financial/practical support. The variable amounts of caring and caring tasks may then form different situations for children; some children may provide care for many hours a day that involves household management and practical tasks, whereas others provide less care but may involve personal or emotional care that affects the child. The combination of these variables may then affect the child's psychological wellbeing (Cunningham et al., 2017).

Taking on caregiving tasks in the family may pose risks for children in their health and in their educational, social, and emotional development (Leu \& Becker, 2017; Pakenham \& Cox, 2015). The risk for adverse outcomes is also shown to increase when the child is responsible for intimate personal care or emotional care (Joseph, Becker, Becker, \& Regel, 2009b) and when the situation with the parent is unpredictable (Pakenham et al., 2007). Despite these risks, caring can also have positive consequences, such as contributing to closeness with family members (Cassidy \& Giles, 2013), a sense of maturity, and daily living skill independence, such as cooking and cleaning (Smyth et al., 2011). Also, not all young carers experience adverse outcomes. Research shows that young carers who find the caring manageable, have social support, and have developed coping strategies experience less distress and better adjustment than children who lack protective factors (Chikradze, Knecht, \& Metzing, 2017; Pakenham et al., 2007).

\section{3 | METHOD}

The empirical data are derived from a pilot study aiming to construct and validate a questionnaire in Swedish, based on validated questionnaires in English that can be used by professionals and researchers to identify children who take on a high amount of caring tasks, and to assess their psychological well-being. The grant for the study was received from the Children's Welfare Foundation Sweden. The study presented here used a mixed methods design in keeping with the definition of Johnson, Onwuegbuzie, and Turner (2007), using both quantitative and qualitative data in order to gain a deeper understanding of the caring activities that children do and their views on their caring. A mixed methods approach is applicable to enhance description and understanding of a largely unknown research field with uncertain answers that rely on interpretations (Mertens, 2014), which is the case of this study with its explorative aim because the knowledge about young carers in Sweden is still scarce (Leu \& Becker, 2017). 


\section{1 | Participants}

The children were recruited through support groups, which is a common form of support in Sweden for children in adverse circumstances due to parental addiction, mental health problems, or violence against a parent (Forinder \& Hagborg, 2008). All children in each group were invited to participate. Thirty children between 10 and 18 years of age took part in this pilot study; 23 girls and 7 boys registered. They were recruited from 5 support groups in various parts of southern Sweden. As participants in a support group, they represent a risk group of having experiences of being young carers, and we presumed they would be able to assist in testing the survey.

\section{2 | Procedure}

This study has been approved by the regional ethical review board in Linköping (ref. 2014/282-31). A central ethical issue in this research has been the balance between protecting vulnerable children from being exposed to additional stress while at the same time respecting the children's skills and allowing them to express themselves about their own lives and experiences in research. Children's own voices are important in the process of increasing knowledge about children's experiences as young carers and for developing appropriate forms of support for them (Eriksson, 2017).

Informed consent was obtained from the children themselves and from the children's guardians in cases where the children were under the age of 15 . The survey and interviews took place during their support group meeting or at a meeting during a camp for adolescents.

The entire survey consisted of 32 questions, taking between 30 and $60 \mathrm{~min}$ to complete. One of the researchers was present, helping out if any question was difficult to read or understand.

\section{3 | Interviews}

Finally, when completing the survey, participants were interviewed lasting 15-30 min in small groups of 3-6 children. Using an interview guide, the children were asked about their experiences related to caring and also about questions asked in the questionnaire. The interviews were then transcribed. In the phase of analysis, the interviews were read and coded thematically into (a) issues children suggested being important and missing in the survey, (b) issues about difficult or wrongly asked questions, and (c) their experiences of caring. For this article, the theme of experiences of caring was further analysed together with survey data.

\section{4 | Measures}

For the original study, we constructed a survey that included several existing questionnaires: sociodemographic variables: The Family Affluence Scale (FAS; Boyce, Torsheim, Currie, \& Zambon, 2006; Currie et al., 2004), assessment of caring variables: Unpredictability of the parent's condition (Pakenham et al., 2007). Multidimensional Assessment of Caring Activities (MACA-YC42), Positive and Negative Outcomes of Caring Questionnaire (PANOC-YC20; Joseph, Becker, Becker, \& Regel, 2009b), What I like and dislike about caring (Joseph, Becker, \& Becker, 2009a). In addition, questionnaires that measure health-related quality of life and psychological well-being: Kidscreen-27 (Ravens-Sieberer et al., 2007) and Strengths and Difficulties Questionnaire (SDQ; Goodman, 2001; Smedje, Broman, Hetta, \& von Knorring, 1999; Svedin $\&$ Priebe, 2008). Those questionnaires not available in Swedish were translated from the original English using a forward-backward translation procedure (Group, 2004; The KIDSCREEN Group, 2004). We used the questionnaires presented below to answer the aim of this article.

\section{5 | Sociodemographic measures}

The children were asked about gender, age, whether they lived together with one parent, a parent and a step-parent, both parents in alternating residence after parental separation, in institutional or foster care, or other. Also, the child and the parents' country of origin was collected.

The FAS, developed in the World Health Organization (WHO) Health Behaviour in School-aged Children Study (Boyce et al., 2006), measures family wealth as described by the child. It comprises four items, for example, Do you have your own bedroom for yourself? $(0=$ No, $1=$ Yes). The composite FAS score ranged between 0 and 7 . Three categories indicating low affluence (score 0-3), middle affluence (score 4.5), and high affluence (score 6.7) have been calculated (Currie et al., 2004). The scale has been validated and found to be useful in analyses that focus on relationships between socioeconomic status and adolescent health (Boyce et al., 2006). Nevertheless, Cronbach's alpha was 0.080 in this study, which is very low.

\subsection{The context of caring activities}

The children were asked, "whom they use to take care of?" with the response alternatives: Mom, Stepmom, Dad, Stepdad, Brother/Stepbrother, and Sister/Stepsister, and with the possibility to mark several alternatives.

Unpredictability of the parent's condition consists of four (Pakenham, Bursnall, Chiu, Cannon, \& Okochi, 2006) or five items (personal communication with K. I. Pakenham). This study used the fiveitem version, and the items referred to a parent or sibling's condition, for example, "It is difficult to plan ahead because my parent's or sibling's condition is unpredictable." Respondents rated on a 5-point scale ranging from 0 (Strongly disagree) to 4 (Strongly agree). A total score ranging from 0 to 20 is calculated, with high values indicating high amount of unpredictability. Cronbach's alpha was 0.702 in this study.

\subsection{The amount and perception of caring activities}

The MACA-YC (Joseph, Becker, Becker, \& Regel, 2009b) measures the amount of caring activity undertaken by the young person over the last month. The MACA-YC18, with 18 items, has been developed from originally 42 items (MACA-YC42) using exploratory principal components analysis, and three response alternatives $(0=$ Never, $1=$ Some of the time, 2 = A lot of the time) are provided. By summing up the responses, an index of the total amount of caring activity is calculated (range 0-36). A score of 18 and above is labelled as "Very high amount of caring activity" (Joseph, Becker, Becker, \& Regel, 2009b). Six subscales are Personal care (e.g., "Help someone you live with to dress or undress"), Sibling care (e.g., "Taking brothers or sisters to school"), 
Domestic tasks (e.g., "Wash up dishes or put dishes in a dishwasher"), Emotional care (e.g., "Keep an eye on someone you live with to make sure they are alright"), Household management (e.g., "Take responsibility for shopping for food"), and Financial/practical (e.g., "Work part time to bring money in"), with three items in each subscale (range 06). Cronbach's alpha in this study was 0.898 (Personal care), 0.756 (Sibling care), 0.597 (Domestic tasks), 0.702 (Emotional care), 0.651 (Household management), 0.593 (Financial/practical), and 0.780 (Total scale); which are somewhat low for most subscales and total scale, but in line with the original scale (Joseph, Becker, Becker, \& Regel, 2009b).

The PANOC-YC2O for young carers (Joseph, Becker, \& Becker, 2009a; Joseph, Becker, Becker, \& Regel, 2009b) measures the subjective cognitive and emotional impact of caring in young people. The questionnaire consists of two 10-item subscales assessing positive (e.g., "Because of caring I feel closer to my family") and negative effects (e.g., "Because of caring I feel very lonely"), with three response alternatives $(0=$ Never, $1=$ Some of the time, and $2=A$ lot of the time). The responses are summed up for each subscale (range 0-20), with high values indicating a high amount of positive or negative effect of caring. Cronbach's alpha in this study was high, 0.906 (positive impact) and 0.918 (negative impact).

What I like and dislike about caring (Joseph, Becker, \& Becker, 2009a) is a short questionnaire with the purpose of providing professionals with information about the nature and extent of caring undertaken, and the young carer's feelings about the caring tasks they do. Young carers are asked how many hours of caring they do on a typical day in a week or at weekends, at what age they first started to do caring jobs, and how many days during the last 2 weeks they have missed or were late for school, college, or university because of caring. Also, young carers are asked to describe, in their own words, what they like, dislike, and find upsetting about caring.

\section{8 | Psychological well-being of the children}

The SDQ (Goodman, 2001; Smedje et al., 1999; Svedin \& Priebe, 2008) is a behavioural screening instrument. The questionnaire consists of five subscales with five items in each: Emotional symptoms (e.g., "I worry a lot"), Conduct problems (e.g., "I get very angry and often lose my temper"), Hyperactivity/inattention (e.g., "I am easily distracted; I find it difficult to concentrate"), Peer relationship problems (e.g., "Other children or young people pick on me or bully me"), and Prosocial behaviour (e.g., "I am kind to younger children"), with three response alternatives ( $0=$ Not true, $1=$ Somewhat true, $2=\mathrm{Cer}$ tainly true). Some of the items have to be reversed when calculating the score for each subscale (range 0-10). The total difficulties score (range 0-40) consists of scores from all subscales despite prosocial behaviour. High values in the prosocial scale indicate strength, while high values in the four other subscales and the total score indicate difficulties.

\section{9 | Analysis}

Percentages for the different categories of sociodemographic variables, such as gender, age, country of origin, and the child's living circumstances were calculated. Scores for total scales and subscales in the MACA-YC, PANOC-YC20, Unpredictability of the parent's condition, and the SDQ, were calculated following the guidelines in manuals and other literature for each scale. Also, means $(M)$ and standard deviations $(S D)$ were calculated for each scale. Normality tests were conducted by calculation of z-values for skewness and kurtosis and visual inspection of histograms, normal Q-Q plots, and box plots for all scales and subscales, separated for gender and age group. The results of the normality tests are not shown in this paper but can be requested from one of the authors (G. P.). For comparisons between boys and girls or between age groups, the independent samples $t$ test was used when the data were normally distributed, and the MannWhitney $U$ test when they were not. For better comparison with previous studies, means and not median values are provided in the tables, even when the data are not normally distributed. Data analysis was conducted using IBM SPSS Statistics 24.

In order to gain insight into whether there might be any tentative pattern in children's views of caring related to how they score their amount of caring, we combined the qualitative data from the interviews and the questionnaire in a mixed-methods analysis. The data of the children with the three highest scores on MACA-42 and the three most negative scores of PANOC were selected. The analysis is therefore based on the scores and quotes from six children. We combined scores and open-ended answers of each child to search for any pattern that describes how children perceive their caring tasks. Children's views of caring are therefore empirically grounded. However, the conceptualization used of a positive, ambivalent, or negative view of caring are to be understood as analytical positions, highlighting the differences in an analysis of what might influence how children perceive their caring.

\section{4 | RESULTS}

\section{1 | Participant sociodemographics}

Majority of the young people in the study (76.7\%) were girls, Table 1. The participants were between 10 and 18 years old with a mean age of 14.87 years $(S D=2.649)$. All participants were born in Sweden, and more than $90 \%$ had one or both parents born in Sweden. Low family affluence was reported by $16.7 \%$ of the youth, and the mean value in the FAS was $4.67(S D=1.269)$. More than half of the young people (53.3\%) lived together with one parent or had alternating residence after parental separation, Table 1.

\subsection{The context of caring activities}

Children in the study are most often helping their mother $(n=21)$; second most common, a sibling ( $n=19)$; and third, their father $(n=15)$. Sixteen children explicitly stated that they help more than one person.

The mean value for unpredictability of the parent's or sibling's condition was $10.66(S D=5.00)$, Table 2 . The range in the sample was 1-19. There were no significant differences between boys and girls or between age groups. There is no given cut-off value for this scale from previous studies that indicates a high amount of unpredictability. In our study, five out of 29 children (17\%) who answered the questions had a total score of 16 or more. 
TABLE 1 Sociodemographic dates $(n=30)$

\begin{tabular}{|c|c|c|}
\hline & & $n(\%)$ \\
\hline \multirow[t]{2}{*}{ Gender } & Girl & $23(76.7)$ \\
\hline & Boy & $7(23.3)$ \\
\hline \multirow[t]{3}{*}{ Age } & $10-12$ & $8(26.7)$ \\
\hline & $13-15$ & 7 (23.3) \\
\hline & $16-18$ & $15(50.0)$ \\
\hline Country of origin, child & Sweden & $30(100)$ \\
\hline \multirow{4}{*}{$\begin{array}{l}\text { Country of origin, } \\
\text { parents }\end{array}$} & Both parents born in Sweden & $23(76.7)$ \\
\hline & $\begin{array}{l}\text { One parent born in Sweden, } \\
\text { one in other country }\end{array}$ & $5(16.7)$ \\
\hline & Both parents born in other country & $1(3.3)$ \\
\hline & Unknown for child & $1(3.3)$ \\
\hline \multirow[t]{3}{*}{ Family Affluence Scale } & Low affluence & $5(16.7)$ \\
\hline & Middle affluence & $16(53.3)$ \\
\hline & High affluence & $9(30.0)$ \\
\hline \multirow[t]{4}{*}{ Siblings } & No sibling/s & $2(6.7)$ \\
\hline & One sibling & $3(10)$ \\
\hline & Two siblings & $10(33.3)$ \\
\hline & Three or more siblings & $15(50 \%)$ \\
\hline \multirow{6}{*}{$\begin{array}{l}\text { Child living together } \\
\text { with }\end{array}$} & One parent & $10(33.3)$ \\
\hline & $\begin{array}{l}\text { Alternating residence after } \\
\text { parental separation }\end{array}$ & $6(20.0)$ \\
\hline & Both parents & $5(16.7)$ \\
\hline & Parent and stepparent & 4 (13.3) \\
\hline & Institution or in foster care & 4 (13.3) \\
\hline & Other & $1(3.3)$ \\
\hline
\end{tabular}

\subsection{The amount and the perception of caring activities}

On average, the children are helping $2.9 \mathrm{hr}$ per weekday (range 0-12, $n=22$ ) and $3.1 \mathrm{hr}$ per day on weekends (range $0-15, n=20$ ). The mean age when they started caring was 8 years of age (range 3-14, $n=22$ ). However, especially the younger children, found it difficult to estimate the amount of time they spent caring.

TABLE 2 Unpredictability of the parent's or sibling's condition $(n=29)$

\begin{tabular}{|c|c|c|c|c|c|c|}
\hline \multirow[b]{2}{*}{ Participant } & \multicolumn{4}{|c|}{ Gender } & \multicolumn{2}{|l|}{ Age } \\
\hline & Range & $\begin{array}{l}\text { Total } \\
M(S D)\end{array}$ & $\begin{array}{l}\text { Girls } \\
M(S D)\end{array}$ & $\begin{array}{l}\text { Boys } \\
M(S D)\end{array}$ & $\begin{array}{l}10-15 \text { years } \\
M(S D)\end{array}$ & $\begin{array}{l}16-18 \text { years } \\
M(S D)\end{array}$ \\
\hline Unpredictability of the parent's or sibling's condition & 0-19 & $\begin{array}{l}n=29 \\
10.66(5.00)\end{array}$ & $\begin{array}{l}n=23 \\
10.70(5.19)\end{array}$ & $\begin{array}{l}n=6 \\
10.50(4.64)\end{array}$ & $\begin{array}{l}n=14 \\
9.50(4.78)\end{array}$ & $\begin{array}{l}n=15 \\
11.73(5.12)\end{array}$ \\
\hline
\end{tabular}

Note. M: mean; SD: standard deviation. Independent-samples $t$ test.

TABLE 3 The amount and the perception of caring activities $(n=30)$

\begin{tabular}{|c|c|c|c|c|c|c|c|}
\hline \multirow[b]{2}{*}{ Participant } & & \multirow[b]{2}{*}{ Range } & \multirow[b]{2}{*}{$\begin{array}{l}\text { Total } \\
M(S D) \\
n=30\end{array}$} & \multicolumn{2}{|l|}{ Gender } & \multicolumn{2}{|l|}{ Age } \\
\hline & & & & $\begin{array}{l}\text { Girls } \\
M(S D) \\
n=23\end{array}$ & $\begin{array}{l}\text { Boys } \\
M(S D) \\
n=7\end{array}$ & $\begin{array}{l}10-15 \\
M(S D) \\
n=15\end{array}$ & $\begin{array}{l}16-18 \\
M(S D) \\
n=15\end{array}$ \\
\hline \multirow[t]{8}{*}{ MACA-YC18 } & Personal care & $0-3$ & $0.13(0.57)$ & $0.13(0.63)$ & $0.14(0.38)$ & $0.07(0.26)$ & $0.20(0.78)$ \\
\hline & Sibling care & $0-4$ & $0.93(1.46)$ & $1.13(1.58)$ & $0.29(0.76)$ & $0.80(1.21)$ & $1.07(1.71)$ \\
\hline & Domestic tasks & $1-6$ & $3.53(1.48)$ & $3.61(1.47)$ & $3.29(1.60)$ & $3.40(1.72)$ & $3.67(1.23)$ \\
\hline & Emotional care & $0-6$ & $1.90(1.71)$ & $1.96(1.85)$ & $1.71(1.25)$ & $2.20(1.90)$ & $1.60(1.50)$ \\
\hline & Household management & $0-6$ & $1.93(1.68)$ & $1.78(1.70)$ & $2.43(1.62)$ & $2.20(1.94)$ & $1.67(1.40)$ \\
\hline & Financial/practical & $0-5$ & $0.60(1.22)$ & $0.65(1.37)$ & $0.43(0.54)$ & $0.60(1.30)$ & $0.60(1.18)$ \\
\hline & Total score & $2-22$ & 9.03 (4.99) & $9.26(5.63)$ & 8.29 (1.89) & $9.27(4.96)$ & $8.80(5.19)$ \\
\hline & & & $n=30$ & $n=23$ & $n=7$ & $n=15$ & $n=15$ \\
\hline \multirow[t]{2}{*}{ PANOC-YC2O } & Positive & $0-20$ & $10.67(5.41)$ & $10.72(4.91)$ & $10.43(7.28)$ & $11.47(6.07)$ & $9.87(4.73)$ \\
\hline & Negative & $0-17$ & $5.90(4.80)$ & $6.22(5.02)$ & & $5.13(4.66)$ & 6.67 (4.97) \\
\hline
\end{tabular}

Note. M: mean; MACA-YC18: Multidimensional Assessment of Caring Activities Checklist for young carers; PANOC-YC20: Positive and Negative Outcomes of Caring; SD: standard deviation. Questionnaire for young carers. Independent samples $t$ test or Mann-Whitney $U$ test. 
TABLE 4 Psychological well-being of the children $(N=30)$

\begin{tabular}{|c|c|c|c|c|c|c|}
\hline & \multirow[b]{2}{*}{ Range } & \multirow[b]{2}{*}{$\begin{array}{l}\text { Total } \\
M(S D)\end{array}$} & \multicolumn{2}{|l|}{ Gender } & \multicolumn{2}{|l|}{ Age } \\
\hline & & & $\begin{array}{l}\text { Girls } \\
M(S D)\end{array}$ & $\begin{array}{l}\text { Boys } \\
M(S D)\end{array}$ & $\begin{array}{l}10-15 \\
M(S D)\end{array}$ & $\begin{array}{l}16-18 \\
M(S D)\end{array}$ \\
\hline SDQ & & $n=30$ & $n=23$ & $n=7$ & $n=15$ & $n=15$ \\
\hline Emotional symptoms & $1-10$ & $5.30(2.51)$ & $5.57(2.63)$ & $4.43(1.99)$ & $4.40(1.96)$ & $6.20(2.73)^{*}$ \\
\hline Conduct problems & $0-7$ & $2.40(1.87)$ & $2.35(1.72)$ & $2.57(2.44)$ & $2.60(2.26)$ & $2.20(1.42)$ \\
\hline Hyperactivity & $0-9$ & $4.97(2.83)$ & $5.09(2.98)$ & $4.57(2.44)$ & $3.93(2.74)$ & $6.00(2.62)^{*}$ \\
\hline Peer problems & $0-7$ & $3.10(1.85)$ & $2.87(1.89)$ & $3.86(1.57)$ & $3.07(2.15)$ & $3.13(1.55)$ \\
\hline Prosocial & $3-10$ & $8.37(1.63)$ & $8.78(1.20)$ & $7.00(2.16)^{* *}$ & $7.73(1.87)$ & $9.00(1.07)^{*}$ \\
\hline Total difficulties score & $5-27$ & $15.77(6.21)$ & $15.87(6.31)$ & $15.43(6.35)$ & $14.00(7.17)$ & $17.53(4.67)$ \\
\hline
\end{tabular}

Note. M: mean; SD: standard deviation; SDQ = Strengths \& Difficulties Questionnaire; $t$ test.

${ }^{*} P<0.05,{ }^{* *} P<0.01$.

three children scoring most negatively on PANOC, point at children taking three differing positions towards caring; "positive towards my caring responsibility," "negative towards my caring responsibility," and "ambivalent towards my caring responsibility." Children with the three highest scores on MACA-42 are taking on a high amount of care. The children, however, position themselves rather differently in viewing the impact of caring in their lives. The analysis of the highest negative scores on PANOC shows that the most negative score comes from a child who scores a medium-level of caring on MACA-42. The findings underline that children may not be caring for a large amount of time as measured by MACA-42, but they may still find the burden of caring to be quite heavy.

The children that take on a high amount of caring activities are either the eldest child or the only child staying with the parent(s). Also, they all live with a parent who misuses alcohol or experiences mental health problems, and they all understand their parent's condition to be unpredictable. All six children reported that they have gained knowledge from their support group about how to take care of themselves.

The differing qualities between the positions described above are related to what kind of tasks the child takes on, if the child feels that he or she receives recognition from the parent for the tasks that he or she is doing, the level of responsibility that the child has to take on, if the child perceives that the caring improves his or her closeness with the family, and if the child can have some self-determination of how much, what, and when he or she will perform the caring tasks.

In Figure 1 below, the three positions towards caring are described, emphasizing the differences between the positions taken by the children.

All children undertake domestic chores, household management, and to some extent, financial/practical tasks. However, personal caregiving tasks for their parents are only experienced by children who express a negative view of caring. Also, emotional care is scored solely by children who express ambivalent or negative views. Some of the things children do not only have something to do with intimate personal care but also with supervising a parent that is not able to take care of herself or himself. A girl tells of the tasks that she dislikes the most:

Take care of my father. I had to shave my father's head when he sat in the bath tub, drunk. (Johanna, 17)

Another crucial aspect is the level of responsibility of caring undertaken by the child. This is not merely a question of the nature of the tasks or the amount of time spent in care, but how much of the responsibility of the caring weighs upon the child. Some children say that they are helping out and doing things together with their parent.

\begin{tabular}{|l|l|l|l|}
\hline \multirow{2}{*}{ Aspects of the } & \multicolumn{3}{|l|}{ Children's' positions towards caring } \\
\cline { 2 - 4 } & Positive position & Ambivalent position & Negative position \\
\hline Tasks & $\begin{array}{l}\text { Domestic chore, } \\
\text { household management } \\
\text { financial support/practical } \\
\text { support }\end{array}$ & Emotional care & $\begin{array}{l}\text { Personal care } \\
\text { Emotional care }\end{array}$ \\
\hline $\begin{array}{l}\text { Level of responsi- } \\
\text { bility }\end{array}$ & $\begin{array}{l}\text { Helping, doing tasks } \\
\text { together with parent }\end{array}$ & Helping out & $\begin{array}{l}\text { High level of respon- } \\
\text { sibility for caring } \\
\text { tasks }\end{array}$ \\
\hline $\begin{array}{l}\text { Self-determination } \\
\text { in caring }\end{array}$ & Some, can take a break & Some, can take a break & $\begin{array}{l}\text { Little, cannot take a } \\
\text { break }\end{array}$ \\
\hline $\begin{array}{l}\text { Parent's view of } \\
\text { child's caring }\end{array}$ & Recognition & Some recognition & Taken for granted \\
\hline $\begin{array}{l}\text { Experience of fam- } \\
\text { ily closeness }\end{array}$ & Improved by caring & To some extent & $\begin{array}{l}\text { Conflicts because of } \\
\text { caring }\end{array}$ \\
\hline
\end{tabular}

FIGURE 1 Children's positions towards caring 
We help each other in our family. I do things to be kind, and everybody does their part at home. (Lisa, 16)

Some children take on full responsibility for managing the tasks at home. The girl below explains her position in the family and the tasks she carries out as a parental responsibility:

Take care of my siblings, take care of my father ... feel like a parent and not like a sibling or their child (Hanna, 18)

The level of responsibility is also connected to how the children perceive if they can choose when they help, with what tasks, and if they can take a break when they feel like it. In the negative position, children experience that they have little possibility to choose what they do and when. Also, they express that they cannot take a break. Children expressing an ambivalent view, think they have some possibility to choose what to do and when, and also express that it is possible to take a break from caregiving.

The caring is undertaken by children interacting with parents, and it seems that the parent's recognition of the child's caregiving is crucial in order to understand how the child perceives doing the caring tasks. Some children experience that parents appreciate and recognize their helping:

I do the shopping, cook and clean. ... it makes my dad happy and proud of me, then I feel happy. (Tilda, 12)

Other children experience that their family relies on them for help and expresses appreciation at times, whereas some children feel that their work at home is taken for granted. In some research, caregiving is perceived as contributing to family-cohesion, and that the child experiences closeness to the family. In this study, the positive position in relation to caring highlights that some children experience that their caregiving makes them feel closer to their family. In contrast, some children taking on the negative position towards caring do not feel that the caring brings them closer to their family. On the contrary, there is quarrelling over the caregiving both with parents and siblings, causing conflicts within the family.

\section{5 | DISCUSSION}

\section{1 | Sociodemographic, age, and gender differences}

This pilot study among Swedish youth at risk reports no differences due to gender or age in the tasks that children perform. There are also few differences in the report concerning psychological well-being, nor were there any differences in the impact of the unpredictability of the parent's or sibling's condition correlating with age or gender. This might be a result of the small sample size and the uneven gender mix. However, the results can be discussed in relation to a broader context, for example, the results from the United Kingdom (Becker, 2007; Joseph, Becker, Becker, \& Regel, 2009b) and Australia (Pakenham et al., 2006) offer insights into the situation of young carers in Sweden.

A comparison with the WHO Health Behaviour in School-Aged Children study from 2001/2002 shows that the reported family affluence was lower among participants in this pilot study. In the WHO study, the mean value in the FAS was 5.8 for Swedish children at age 11, 13, or 15 (Boyce et al., 2006) and $9.2 \%$ of them reported low family affluence (Currie et al., 2004) as compared with a mean value of 4.7 and with low family affluence of $16.7 \%$ in our study. Parental problems such as mental health issues and alcohol or drug addiction have been shown to be related to economic problems (Hjern \& Manhica, 2013) whereas low family affluence is associated with poorer health among young people (Currie et al., 2004). The small sample size in this pilot study did not allow for analyses involving the relative contributions of parental problems/need for care and family affluence in the psychological well-being of young persons. This could be an important issue for future research.

\section{2 | Caring tasks and amount of care activities}

The children in our study report a lower amount of caring activities for different types of caring activities in MACA-YC18 than youth in the Joseph et al. (2009b) study from the United Kingdom, with domestic tasks as the exception. The amount of emotional care as scored by the Swedish children is lower. In both studies, there were no significant differences between boys and girls with the exception of British girls reporting a higher amount of personal care.

\section{3 | Psychological well-being}

Malmberg, Rydell, and Smedje (2002) developed clinical cut-off values for the SDQ total difficulties score and the five subscales, based on parent reports on 5- to 15-year-old children from a community sample and a child psychiatric sample in Sweden. At the group level, the children in our study reported values above the clinical cut-off for the total difficulties score, emotional symptoms, hyperactivity, and peer problems. Also, when compared with a population-based sample of Swedish 17-19 year old youth (Svedin \& Priebe, 2008), the 16-18 year old youth in our sample reported more emotional symptoms, hyperactivity, and peer problems, but also more prosocial behaviour. Although the samples are not completely comparable, there is some indication that the children in our study perceive more mental health symptoms, and thus a lower degree of psychological well-being.

\subsection{Children's descriptions of impact of caring}

Although the reported amount of caring activities was lower in the Swedish sample as compared with the above-mentioned British study, Swedish youth reported less positive and more negative outcomes of caring for young carers in PANOC-YC20. We found no gender differences in the Swedish sample, although boys reported significantly more positive outcomes than girls in the British study.

Research has pointed out that personal care often involves the tasks with most negative impact on children (Becker, 2007; Cunningham et al., 2017). The finding of our study is congruent with this. The most negative scores on PANOC entail personal care of a parent. Furthermore, the most negative scores on PANOC also indicate that children supervise the parent and worry about the parent when not at home. The findings suggest that this emotional care is perceived to be a heavy and negative responsibility to take on for a child. Our findings of the three differing child positions of caring as negative, 
ambivalent, and positive, further underline that the negative consequences are linked to emotional and personal care. Therefore, it is important to measure the emotional care and level of psychological worrying experienced by children.

\section{5 | Circumstances of importance for children's views of their caring responsibilities}

An important circumstance influencing children's views of caring is the unpredictability of the situation. Pakenham et al. (2006) report approximately the same mean value for unpredictability of the parent's condition $(M=10.42, S D=3.74)$ that we found in our study $(M=10.66, S D=5.00)$, although they used only four items as compared with five items in our study. This indicates that the children in our study perceived their parent's or sibling's condition as less unpredictable than the youth in the Australian study by Pakenham et al. The participants in the Pakenham et al. study were 100 young caregivers between 10 and 25 years old, with a variation in recruitment methods including support groups for children of parents with a mental illness or physical disability.

Another aspect of importance for how children view their caring is the level of responsibility that children experience. The level of responsibility does not merely have to do with hours of caring or the specific task. It has to do with the level of responsibility for caring such as managing the household and being responsible for their parent's psychological well-being and personal care. The ambivalent and positive views of caring indicate that the responsibility is shared with a parent, but in a negative view, the children perceive that they are alone in carrying the responsibility for that task.

\section{6 | Study limitations}

Due to the small number of participants in this pilot study and the specific sample from children at risk taking part in a support group, there is no claim of being representative for children's caring experiences overall, or even in Sweden. Children with a non-Swedish background are underrepresented in the study. Also, children placed in out-ofhome care are overrepresented in the study. This is possibly reflected in low ratings on psychological well-being and adverse experiences of caring, although they are not doing any caring in their current situation. However, in combining the quantitative data with the interviews presenting the children's experiences of caring, this article presents some insights into the responsibilities of caring and the impact on children's lives.

\section{7 | Conclusions and implications}

Summing up the results of this study, the main finding is that the children in our study reported less psychological well-being and quality of life than children in the general population. Some children reported clinical values. The second main result is that the characteristics of the care reported by Swedish children differ from the care described by children who took part in studies in the United Kingdom. Swedish children provide a lower amount of care, but they report a higher degree of negative consequences and lower psychological well-being than young carers in other countries. How is this to be interpreted?
One explanation may be found in the societal view of children taking on responsibilities for caring which might differ among different welfare societies and cultures. In comparison, the United Kingdom has developed various forms of support and also carer allowance for young carers (Leu \& Becker, 2017). The response of the Swedish welfare state on the contrary is that children are to be protected from caregiving responsibilities because it could be considered as child labour and goes beyond the responsibilities that should be entrusted on a child. The welfare policy is therefore all about protecting children and not to develop support for children who despite the intentions are caregivers. Therefore, children gain little recognition for what they do as carers, and they may even feel that they are doing tasks they should not be doing. The view of the protective welfare state paradoxically then conceals the experiences of children who do take on caring tasks. This pilot study is the first step of the development of a Swedish assessment tool for identifying young carers. A revised version of the survey could be useful, for example, in social services or healthcare in order to identify young carers and provide the support they may need.

The implication of this study is that further studies need to investigate not only the magnitude and the consequences of children taking on caring responsibilities, but also children's experiences of taking on caring responsibilities, in order to develop a social policy that recognizes and provides adequate support for these children.

\section{ACKNOWLEDGEMENTS}

The article is written with acknowledgements to Children's Welfare Foundation Sweden, which funded the study.

\section{ORCID}

Ulrika Järkestig-Berggren (D) http://orcid.org/0000-0002-1325-9965

Ann-Sofie Bergman (D) http://orcid.org/0000-0001-5202-0722

Maria Eriksson (iD http://orcid.org/0000-0002-7261-6643

Gisela Priebe (D) http://orcid.org/0000-0001-8386-8881

\section{REFERENCES}

Eriksson, M. (2017). Childrens'voices, children's agency and the development of knowledge about children exposed to intimate partner violence. In M. Husso, T. Virkki, M. Notko, H. Hirvonen, \& J. Eilola (Eds.), Interpersonal violence: Differences and connections (pp. 140-152). Oxon: Routledge.

Becker, S. (2007). Global perspectives on children's unpaid caregiving in the family: Research and policy on 'young carers' in the UK, Australia, the USA and Sub-Saharan Africa. Global Social Policy, 7, 23-50. https://doi.org/10.1177/1468018107073892

Becker, S., Aldrige, J., Brittian, D., Clasen, J., Dietz, B., Gould, A., \& Hantrais, L. (1995). Young carers in Europe-An exploratory cross-National Study in Britain, France, Sweden and Germany. Leicestershire: Department of Social Sciences: Lougborough University.

Bergman, A.-S. (2016). In a proper home. Journal of Family History, 41, 176-191. https://doi.org/10.1177/0363199016635493

Boyce, W., Torsheim, T., Currie, C., \& Zambon, A. (2006). The family affluence scale as a measure of national wealth: Validation of an adolescent self-report measure. An International and Interdisciplinary Journal for Quality-of-Life Measurement, 78, 473-487.

Cass, B., Smyth C., Hill T., Blaxland M. \& Hamilton, M. (2009) Young carers in Australia: Understanding the advantages and disadvantages of their care giving. Social Policy Research Paper No.38, Australian government. 
Cassidy, T., \& Giles, M. (2013). Further exploration of the young carers perceived stress scale: Identifying a benefit-finding dimension. British Journal of Health Psychology, 18, 642-655. https://doi.org/10.1111/ bjhp.12017

Chikradze, N., Knecht, C., \& Metzing, S. (2017). Young carers: Growing up with chronic illness in the family-A systematic review. Journal of Compassionate Health Care, 4.

Cunningham, L. C., Shochet, I. M., Smith, C. L., \& Wurfl, A. (2017). A qualitative evaluation of an innovative resilience-building camp for young carers. Child \& Family Social Work, 22, 700-710. https://doi.org/ $10.1111 / \mathrm{cfs} .12286$

Currie, C. E., Roberts, C., Morgan, A., Smith, R., Settertobulte, W., Samdahl, O., \& Barnekow Rasmussen, V. (2004). In C. E. Currie, C. Roberts, A. Morgan, R. Smith, W. Settertobulte, O. Samdahl, \& V. Barnekow Rasmussen (Eds.), Young people's health in context health behavior in school-aged children. Copenhagen Denmark: World Health Organization.

Forinder, U., \& Hagborg, E. (2008). Stödgrupper för barn och ungdomar [Support groups for children and young people]. Studentlitteratur, Lund.

Goodman, R. (2001). Psychometric properties of the Strengths and Difficulties Questionnaire. Journal of the American Academy of Child \& Adolescent Psychiatry, 40, 1337-1345. https://doi.org/10.1097/ 00004583-200111000-00015

Group, K. (2004) Translation \& validation procedure.

Hjern, A., \& Manhica, H. A. (2013). Barn som anhöriga till patienter i vårdenhur många är de? [Children as next of kin: How many are they?]. Kalmar: Linnaeus University.

Johnson, R. B., Onwuegbuzie, A. J., \& Turner, L. A. (2007). Toward a definition of mixed methods research. Journal of Mixed Methods Research, 1, 112-133. https://doi.org/10.1177/1558689806298224

Joseph, S., Becker, F., \& Becker, S. (2009a). Manual for measures of caring activities and outcomes for children and young people. London.

Joseph, S., Becker, S., Becker, F., \& Regel, S. (2009b). Assessment of caring and its effects in young people: Development of the Multidimensional Assessment of Caring Activities Checklist (MACA-YC18) and the Positive and Negative Outcomes of Caring Questionnaire (PANOC-YC20) for young carers. Child: Care, Health and Development, 35, 510-520.

Kallander, E.K., Weimand, B.M., Becker, S., Van Roy, B., Hanssen-Bauer, K., Stavnes, K., Faugli, A., Kufås E. \& Ruud, T. (2017) Children with ill parents: Extent and nature of caring activities. Scandinavian Journal of Caring Sciences, doi: 101111/scs.12510

Leu, A., \& Becker, S. (2017). A cross-national and comparative classification of in-country awareness and policy responses to 'young carers'. Journal of Youth Studies, 20, 750-762. https://doi.org/10.1080/ 13676261.2016.1260698

Malmberg, M., Rydell, A.-M., \& Smedje, H. (2002). Validity of the Swedish version of the Strengths and Difficulties Questionnaire (SDG-SWE). Nordic Journal of Psychiatry, 57, 357-363.
Mertens, D. M. (2014). Mixed methods and wicked problems. Journal of Mixed Methods Research, 9, 3-6.

Nordenfors, M., Melander, C., \& Daneback, K. (2014). Unga omsorgsgivare i Sverige [Young Carers in Sweden]. Kalmar: Nationellt kompetenscentrum anhöriga.

Pakenham, K., \& Cox, S. (2015). The effects of parental illness and other ill family members on youth caregiving experiences. Psychology \& Health, 30, 857-878. https://doi.org/10.1080/08870446.2014.1001390

Pakenham, K., Bursnall, S., Chiu, J., Cannon, T., \& Okochi, M. (2006). The psychosocial impact of caregiving on young people who have a parent with an illness or disability: Comparisons between young caregivers and noncaregivers. Rehabilitation Psychology, 51, 113-126. https:// doi.org/10.1037/0090-5550.51.2.113

Pakenham, K., Chiu, J., Bursnall, S., \& Cannon, T. (2007). Relations between social support, appraisal and coping and both positive and negative outcomes in young carers. Journal of Health Psychology, 12, 89-102. https://doi.org/10.1177/1359105307071743

Ravens-Sieberer, U., Auquier, P., Erhart, M., Gosch, A., Rajmil, L., Bruil, J., ... Kilroe, J. (2007). The KIDSCREEN-27 quality of life measure for children and adolescents: Psychometric results from a cross-cultural survey in 13 European countries. Quality of Life Research, 16(8), 1347-1356. https://doi.org/10.1007/s11136-007-9240-2

Smedje, H., Broman, J.-E., Hetta, J., \& von Knorring, A.-L. (1999). Psychometric properties of a Swedish version of the 'Strengths and Difficulties Questionnaire'. European Child \& Adolescent Psychiatry, 8, 63-70. https://doi.org/10.1007/s007870050086

Smyth, C., Cass, B., \& Hill, T. (2011). Children and young people as active agents in care-giving: Agency and constraint. Children and Youth Services Review, 33, 509-514. https://doi.org/ 10.1016/j.childyouth.2010.05.009

Svedin, C. G., \& Priebe, G. (2008). The Strength and Difficulties Questionnaire as a screening instrument in a community sample of high school seniors in Sweden. Nordic Journal of Psychiatry, 62.

Trondsen, M. (2013) "Vi er ikke syke mennesker- vi har bare et behov for å snakke" En kvalitativ studie av en internettbasert selvhjelpsgruppe for ungdom med en psykisk syk forelder. ["We are not sick people- we just need to chare" A qualitative study of a web-based self-support group for adolescents with a mental health ill parent]. Dissertation, University of Tromsö, Tromsö.

How to cite this article: Järkestig-Berggren U, Bergman A-S, Eriksson M, Priebe G. Young carers in Sweden-A pilot study of care activities, view of caring, and psychological well-being. Child \& Family Social Work. 2019;24:292-300. https://doi.org/ $10.1111 /$ cfs.12614 